\title{
Discovery and Practice of EDA Experimental Teaching Reform
}

\author{
Xianmin Wei
}

\author{
Computer and Communication Engineering School of Weifang University, Weifang, China
}

\begin{abstract}
EDA experiment is one of practical, professional and highly specialized basic application courses in electronic communications professional, how to use EDA laboratory? How to carry out EDA experimental teaching in order to improve teaching effectiveness? These are issues by EDA teaching staff to think and explore. In this paper, with the shortcomings and deficiencies of experimental teaching of traditional EDA, combined the teaching practice of Weifang University, proposed experimental teaching reform thinking of EDA with teaching system systematic, open and teaching methods, teaching evaluation comprehensive, complete security system experiment.
\end{abstract}

Index Terms: EDA experiments; teaching reform; innovation

(C) 2011 Published by MECS Publisher. Selection and/or peer review under responsibility of the International Conference on E-Business System and Education Technology

\section{Introduction}

With the development of information society and popularity of electronic products, electronic communications majors are also slowly into the major universities, with the same time electronic communications students course education are increasingly being pay attention by the teachers and students. Electronic Design Automation (EDA) course is a theoretical, practical and strong professional foundation courses in electronic information majors, it is a strong impact on the traditional method of electronic design, and is modern trends of electronic design. In recent years, EDA technology has gone quietly into the college classroom, and all colleges and universities are active in the EDA teaching, have established EDA Laboratory. EDA lab should be how to use, how to carry out EDA experimental teaching to improve teaching effectiveness, is the issues by EDA teaching staff to think and explore. The effect of experimental teaching and methods are a direct impact on the teaching profession. This article is for my school in the EDA experimental teaching reform to make some comments and suggestions.

EDA experiment is electrical specialty course with practical, strong application and quite rapid update of its content. The introduction of the latest achievements in the field of foreign EDA to improve our school environment, teaching courses in electrical, development environment of international electronic design is of convergencewith education mode, for the training of innovative talents in the new century is the construction of our school in EDA Laboratory. To stimulate student interest in learning and strain quality, innovative

* Corresponding author.

E-mail address:wfxyweixm@126.com 
consciousness, innovative spirit and creative ability, to improve their practical ability, and identify problems, analyze and solve problems, is the general idea of reform of EDA experimental teachingin my school. Concrete reform measures embodied in four perfect security systems of the teaching system systematic, open and teaching methods, teaching evaluation comprehensive, experimental.

\section{Systematic teaching system}

For a long time, basic experimental teaching is strict limits with professional experimental teaching, lack of coordination, resulting in duplication of course content, teaching investment repeat experiment, basic experimental teaching are out of touch with the professional situation, having a serious impact on teaching. Therefore, the need for experimental teaching system reform, to break the basic experiment experimental and professional boundaries, to strengthen basic and applied communication and close contact, comprehensive, integrated, practical ability of engineering students.

To reform the traditional teaching system, to consider the integrity of subject knowledge and linkages, to integrate the original scattered, isolated experiments of the course and a separate set of experiments into curriculum and advanced technology and teaching methods throughout the entire process. Electronic circuit design, for example, for communications majors the design task is to disign digital frequency synthesizer, this design method requires students to achieve digital frequency synthesizer, and then through the digital-analog conversion chip to convert analog signals, and then filtered using low pass filter high frequency components, resulting in relatively smooth sine and cosine signals. This is an experimental combination of analog circuits, digital circuits, high frequency electronic circuits, communication theory such as the contents of several courses. This course is very well based on experimental and professional cross-experiment, to overcome the disadvantages of repeated teaching content, saving hours of experimental teaching; but also conducive to the sharing of resources and laboratory experiments unified rational deployment of personnel and improve the instruments and equipment utilization and laboratory management.

\section{Open teaching methods}

Re-integration of teaching system and teaching methods is the reform of two important experimental teaching components for EDA comprehensive reform. Change of teaching to provide a basis for the integration of the teaching system, also for the integration of the teaching system to be implemented to provide a guarantee.

To change the traditional teaching methods into the open experiment experimental teaching methods is reform of EDA teaching in our school. The traditional experimental teaching methods, limits the ability of the students hands and thinking innovation play. Open experiment paid great attention to teaching students the main role, to play a prominent personality of students, focusing on stimulating the enthusiasm of students in active learning, emphasize the students ability and innovative sense. Opening of the experimental teaching not only means test time, test equipment and test site open, but also the main experimental methods of teaching content and opening experiment. Specifically, in the following areas:

\section{A. Reducing Validation Experiments, Increasing Comprehensive Experiment}

More traditional teaching content is to verify the experiment, teachers guide students to experiment, primarily to verify a theorem or conclusions. In the confirmatory experiment, the students are provided instruction in accordance with the experimental test content, test methods and test procedures step by step to do experiments. This experiment allows students to master the basic experimental methods, learn the proper use of equipment and operating skills, which in the initial stage of the experiment the students is necessary. But this experiment can not make the theory with practice, and easily to enable students to produce dependence, loss of initiative, creative play is not conducive to the students, severely restricted the cultivation of student awareness of innovation and hinder the enthusiasm of the students take the initiative to explore. Therefore, EDA experimental teaching, should be content to minimize the verification experiment, a corresponding increase in comprehensive experiments. 
Comprehensive experiment is a combination of multi-course content which is closely related with the real-life subject. In a comprehensive study, teacher involved is relatively small, the experimental subject is students, teachers, test requirements are given, the students themselves access to information, to establish pilot program, and then the experimental design. The experiment will not only help students to deepen the understanding of theoretical knowledge, but also to enable students to improve the independent analysis, problem-solving abilities and cultivate a sense of innovation and innovation.

\section{B. The Teaching Method from the "indoctrination" to a "heuristic"}

In modern teaching theory, teachers are not teaching students to transfer knowledge to the process, but the teachers to provide students with the learning environment, organizing students to participate in and guide the students learning process. In order to abandon the traditional "examination" as the goal of "indoctrination", "spoon-feeding" the process of teaching, the university established a "heuristic", "discussion" of classroom teaching. Start by teachers out of some basic issues, inspire students to supplement the basic issues to see if the subject can have more features and more practical to cover more of the knowledge points, then we encourage students to observe life on your own topic. The realization of the project, teachers mainly from the ideas and methods to guide students, practical scheme designed by the students themselves to study and personally verify the correctness of the design on the machine. This previously by the teachers "take hold" of the teaching process, become a teacher, "held on to go," and even students "find their own path," the teaching process. In this process, students in all aspects of the capacity has been exercise.

Practice has proved that our training methods and means of giving the students the intrinsic motivation for learning, curiosity, passion, fun and enthusiasm to create a good academic atmosphere. In this process, students are no longer passive recipients of knowledge, but knowledge initiative, participants, explorers. Strain the quality of students, sense of innovation, creativity, problem solving and in the continuing active participation during the process of training.

\section{Individualized}

In order to fully tap the potential of each student, we propose different students with different levels of requirements. Such as curriculum design of a basic requirement for students, as well as an enhanced part of the requirements, the basic requirement is that each student must meet, and raise the claim will be made for students who have the ability, so you can ensure that every student have been fully display their talents. Through years of practice, we found that as long as they give them enough space, the students develop their potential is endless.

\section{Comprehensive assessment of teaching}

Appraisal is an important part of the process of personnel training, teaching effectiveness and to test the primary means of teaching quality. Examination method of assessing the past only the ability of the students rather than the real exam flexible application capabilities, the engineering students, engineering practice is precisely why they need it most.

For this deficiency in experimental teaching evaluation system, we carry out reforms. After the reform of the examination, including basic skills assessment test and Integrated Skills two blocks. Basic skills assessment test results for $30 \%$ of the total score, the examination on the basic end of the experiment, the main test students mastery of basic knowledge as well as familiarity with experimental equipment in order to urge them to quickly master the basic skills for later pave the way for the integrated design. Comprehensive ability test results for $70 \%$ of the total score, the assessment of basic skills assessment in the after arrangement, it can be a variety of ability of students to conduct a comprehensive assessment. Teachers, the students staged a certain degree of difficulty of a comprehensive design project that requires students to self-access to relevant information, develop a better design, and through laboratory equipment to complete the design. After the design is completed, the "answer" the way to do reporting. Students design their own questions about the design for the concept, achievement, problems encountered, solutions and so on, teachers and other students may ask questions at any time, but also describes his own views. Integrated Skills Assessment results, mainly based on the content of the novel and experimental practicality, feasibility and optimization of experiments, experimental equipment, the correctness 
of the selected experimental data analysis is reasonable, comprehensive and defense lab report fluency and other aspects.

This assessment method not only examine the students the basic knowledge and basic skills to master the situation, but also examines the integrated use of the knowledge the students analyze and solve problems, but also stimulate the students interest in learning, training the students take the initiative to learn new knowledge and ability to guide students to the learning.

\section{Perfect experimental security system}

After college enrollment, major colleges and universities are facing the basic problem of insufficient experimental resources, but many laboratories because there are varying degrees of fragmentation, lack of unified coordination and management shortcomings, but also caused some experimental waste of resources and laboratory personnel. To avoid the appearance of this contradiction, the university created EDA Laboratory by specialized personnel management, they are responsible for laboratory management and maintenance of laboratory equipment, laboratory equipment to ensure high load state in the still normal operation.

In the Traditional teaching, the experimental and theoretical teaching is teaching completely independent, experimental teaching conducted by specialized laboratory personnel, often in large part caused by a mismatch between theory and practice. EDA experimental school I teach theory courses entirely by the teachers in charge of the backbone, they can teach lessons according to the theoretical situation of reasonable arrangements for experiments, but also in the process about the theory course, the ability of teachers to students has a clear understanding, so that In EDA experimental teaching to students of different levels can be individualized differences, so that each student's potential can be fully tapped.

In order to protect the integration of basic experimental and professional experiments, in addition to our school computer lab outside of EDA, EDA is also equipped with a test box, test boxes and embedded systems QuartusII, Multisim, EWB, PAC-Designer, Matlab, System View, Labview circuit design and simulation software, this can also create a variety of laboratory experiments in the EDA program, for student learning provides great convenience.

\section{Conclusion}

Practice shows that EDA experimental teaching in my school meets scientific and technological progress and social development with the quality of talent required, in line with educational development and reform of teaching the basic rules, adapted to new trends in innovation and personnel training, and achieved remarkable results. However, EDA experimental teaching reform is an ongoing difficult task with a long way to go, it will develop with the development of the times. Therefore, we need to further deepen the EDA teaching reform, improve the test management approach, adjustment, expansion of laboratory capabilities to continuously improve the experiment content, experimental means and methods to strengthen the laboratory team, and raise the quality of laboratory personnel to better meet the current requirements of the rapid development of electronic technology.

\section{References}

[1] Min Cui, Xiangming Deng,"Reform experiment teaching methods to develop ability of engineering practice.” Experimental Technology and Management, 2001,Vol.18,No.3,pp. 118-120.

[2] Ming Bao, Donglin Peng, Wei Qian, "To carry out EDA teaching cultivating high quality talents." Chongqing Institute of Technology, 2004,Vol.18,No.5,pp.179-180.

[3] Xiangling Du, Jingli Wang, Bo Liang, "interest in iron. On the EDA Laboratory." Liaoning Institute of Technology, 2002,Vol.4,No.2,pp. 91-92.

[4] Zhaosheng Lai, Lixin Guan. "EDA Technology and Electronic Circuit Experiment Teaching." Gannan Teachers College, 2005,Vol.6,No.3,pp. 93-94. 
[5] Fenglin Li. "Electrical Courses introduce the teaching of EDA." Electrical \& Electronic Education, 2001, Vol.06,pp.17-19.

[6] Zhijiang Xie, Hongyan Sun, Hesheng Jiang, Jisheng Zhang. "Case Method in Teaching of Engineering." Higher Engineering Education, 2003, No.05,pp.75-77.

[7] Xiushan Liu. "EDA teaching and ability of modern electronic design." Guangdong Polytechnic Normal University, 2004,No.04,pp.92-94. 